\title{
THE RESEARCH OF DRIVER'S GAZE AT THE TRAFFIC SIGNS
}

\author{
Martin Hudák ${ }^{1}$, Radovan Madleňák ${ }^{2}$
}

\begin{abstract}
Traffic signs provide drivers with appropriate warnings and information and signal legal requirements and directions. The aim of this article is to research the frequency and duration of a driver's gaze at traffic signs. The selected stretch of road in the Slovak Republic has been subjected to a high number of traffic accidents with the most common causes reported as incorrect driver behavior and distracted driving. Therefore, the study's objective is to measure the time drivers spend looking at billboards. To achieve this outcome, the study uses eye tracking glasses, which are designed to record a person's natural gaze behavior in real-time. Previous research has shown that the average time gazing at a billboard is 0.543 seconds. The article also contains a comparison of driver's gaze at different traffic signs and billboards. The economic quantification of traffic accidents on the selected road is also included in the article.
\end{abstract}

UDC Classification: 656.1 DOI: http://dx.doi.org/10.12955/cbup.v4.870

Keywords: Traffic, signs, driver, billboards, accidents.

\section{Introduction}

The essential element of the human-vehicle-environment is the human, most often as a driver. When designing road-traffic infrastructure and transport-engineering measures, it is necessary to consider how these facilities and measures will affect road users and be understood and accepted. Traffic signs serve as highly critical information systems to ensure safety, efficiency, and continuity of road traffic (Beijer, 2004). Traffic signs inform the driver about road conditions, dangerous sections of the road, lack of road interchange, or other relevant circumstances. Horizontal traffic signs are used to ensure traffic and road safety, regulate traffic, guide drivers and pedestrians using the roads, provide information regarding the roads, and specify restrictions and prohibitions (Kalasova, 2015). These markings consist of lane and shoulder lines, zebra lines on level crossing for the safety of pedestrians, text and symbols, 'slow down' warning lines, and speed bumps (or speed breakers). Vertical traffic signs are applied to specify rules that drivers and pedestrians who use the road must adhere to and that are used for routing and information purposes. Vertical traffic signs consist of traffic warnings signs, traffic information signs, and traffic regulatory signs (Johansson, 1966).

The most common causes of traffic accidents in the Slovak Republic involve driver behavior and distraction. A possible driver distraction is the 'visual pollution' from the roadside advertisement (Edquist, 2011). This may, not only attract the driver's attention, but also influence the driver's psyche. With the plentitude of advertisements, traffic signs may merge with 'visual pollution'. In many cases, visual pollution has a negative impact on driver behavior (Chattington, 2009).

The main objective of this article is to research the driver's gaze at the traffic signs on selected roadways. Another objective is to measure the driver's gaze at the billboards. The article also compares the driver's gaze at the traffic signs with their gazes at the billboards.

\section{Methodology}

To be able to solve the objectives of this article, we used the following methods, techniques, and tools:

The statistics for traffic accidents from the Traffic Inspectorate in Žilina;

SensoMotoric Instruments (SMI) Eye Tracking Glasses to collect data on the drivers' visual behavior in actual traffic conditions. These eye tracking glasses are lightweight and designed to record a person's natural gaze behavior in real-time in a broad range of applications; and

The SMI BeGaze eye tracking software to analyze and structure information from experiments and study subjects, as well as display the eye tracking data as meaningful graphs, all in one advanced application.

\footnotetext{
${ }^{1}$ Martin Hudák, Department of Communications, The Faculty of Operation and Economics of Transport and Communications, University of Žilina, Žilina, Slovak Republic, martin.hudak@fpedas.uniza.sk

${ }^{2}$ Radovan Madleňák, Department of Communications, The Faculty of Operation and Economics of Transport and Communications, University of Žilina, Žilina, Slovak Republic, radovan.madlenak@fpedas.uniza.sk
} 


\section{The Analysis}

The selected roadway is between Žilina and Martin in northern Slovakia. It is a stretch of road that forms part of the primary road, number $18(\mathrm{I} / 18)$. The length of the selected stretch is $14 \mathrm{~km}$. The reasons for selecting this particular road stretch were: 1) its high level of traffic density; 2) its high number of traffic accidents; and 3) the high number of advertisements placed next to this stretch of roadway (Madlenak, 2014). The selected road stretch is shown in Figure 1.

Figure 1: The selected roadway between Žilina and Martin

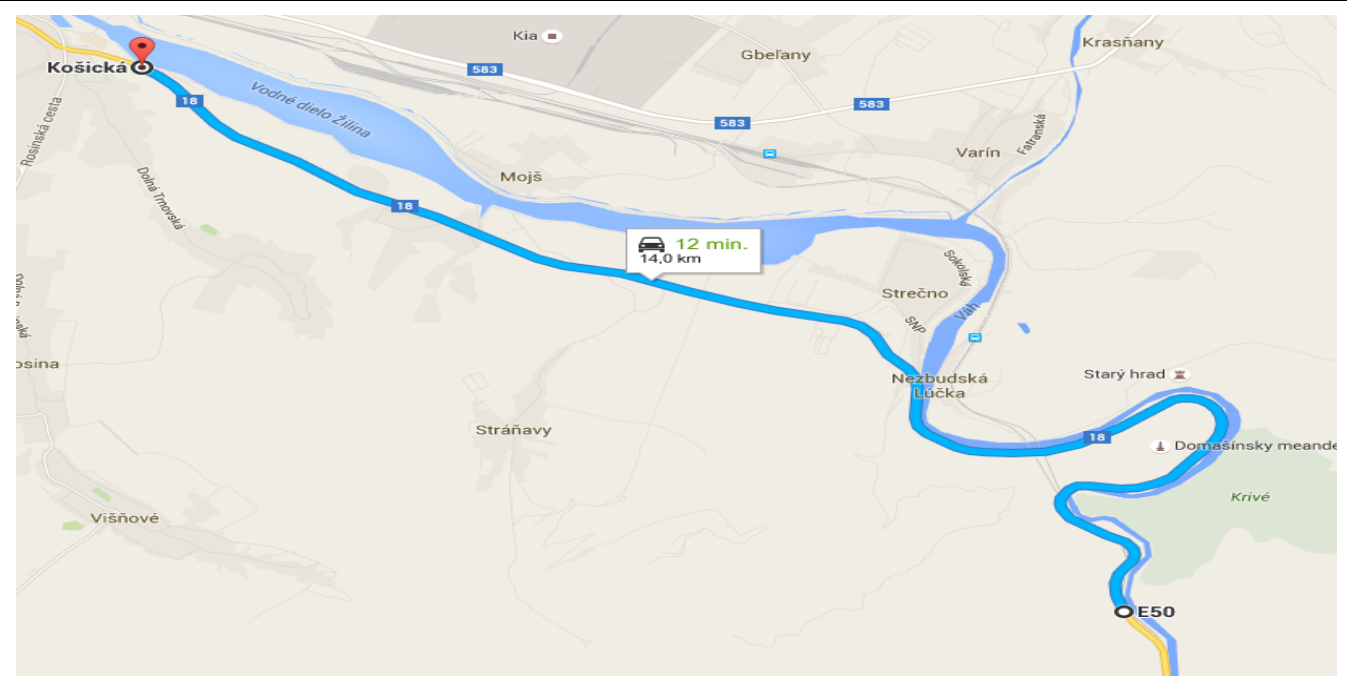

Source: Authors

The statistics regarding traffic accidents on the selected road stretch are shown in Table 1. Table 1 shows that there was a total of 21 traffic accidents on the selected road stretch, with the most common cause of incorrect driver behavior, occurring in 19 cases. More details of the traffic accidents are shown in Table 1.

Table 1: The statistics of traffic accidents on selected roadway between Žilina and Martin on the primary road, number $18(\mathrm{I} / 18)$

\begin{tabular}{|l|c|c|}
\hline \multicolumn{1}{|c|}{} & 1 Jan 2015-30 Sep 2015 & 1 Jan 2014-30 Sep 2014 \\
\hline Total number of traffic accidents & 21 & 12 \\
\hline Number of road traffic deaths & 4 & 3 \\
\hline Number of serious injuries & 9 & 3 \\
\hline Material damage $(€)$ & 7 & 45300 \\
\hline
\end{tabular}

Source: Authors

There was a total of 124 vertical traffic signs on the selected roadway. Vertical traffic signs in the Slovak Republic are divided into five main groups: 1) traffic warning signs for the driver to take extra care; 2) traffic regulatory signs to regulate the priority of driving; 3 ) traffic prohibition signs to display the prohibitions or restrictions; 4) traffic command signs to regulate the driving direction; and 5) traffic information signs to guide road users along routes. The latter informs drivers about the distance to the next destination, points of geographical or historical interest, and other information for the ease, safety, and satisfaction of the road traveler (Kubikova, 2014).

The visual pollution next to the selected road stretch involved a series of 348 adjacent advertisements. With absence of relevant legislation in Slovakia, a high number of billboard placements could be illegal. Within a distance of $28 \mathrm{~km}$ of roadway, on average, one advertisement is placed every 80 meters of the road, with $95 \%$ of roadside advertisements being classic billboards (size $510 \times 240 \mathrm{~cm}$ ). 
Figure 2: The example of visual pollution next to the selected road stretch between Žilina and Martin on the primary road, number $18(\mathrm{I} / 18)$

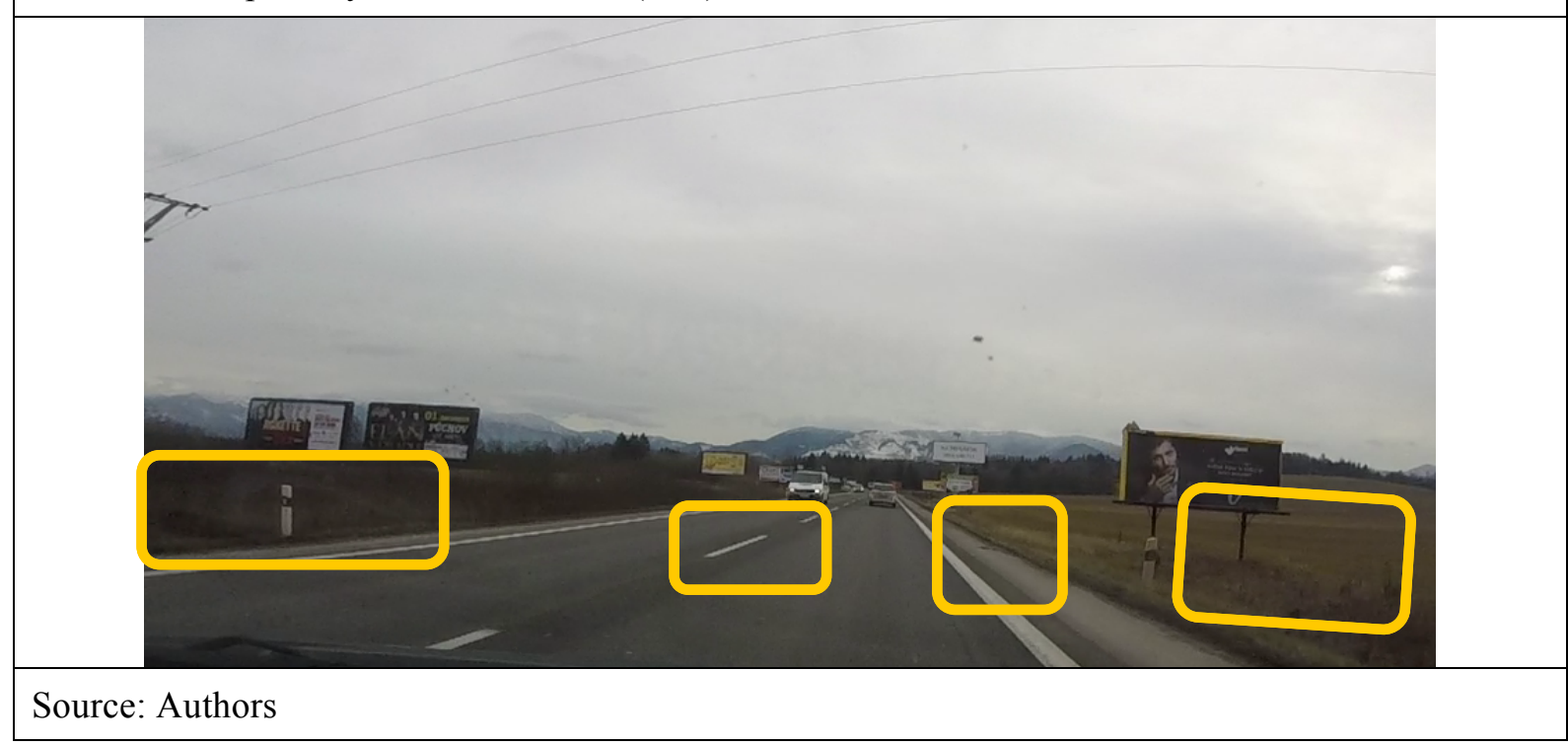

\section{Results and Discussion}

As mentioned above, driver behavior in terms of eye gaze was tested by SMI eye tracking glasses, in well-lit daylight conditions. The total time for return travel along the selected road was approximately 27 minutes by car. An example of the analysis for examining the driver's gaze at the traffic signs and billboards, using SMI BeGaze software, is shown in Figure 3.

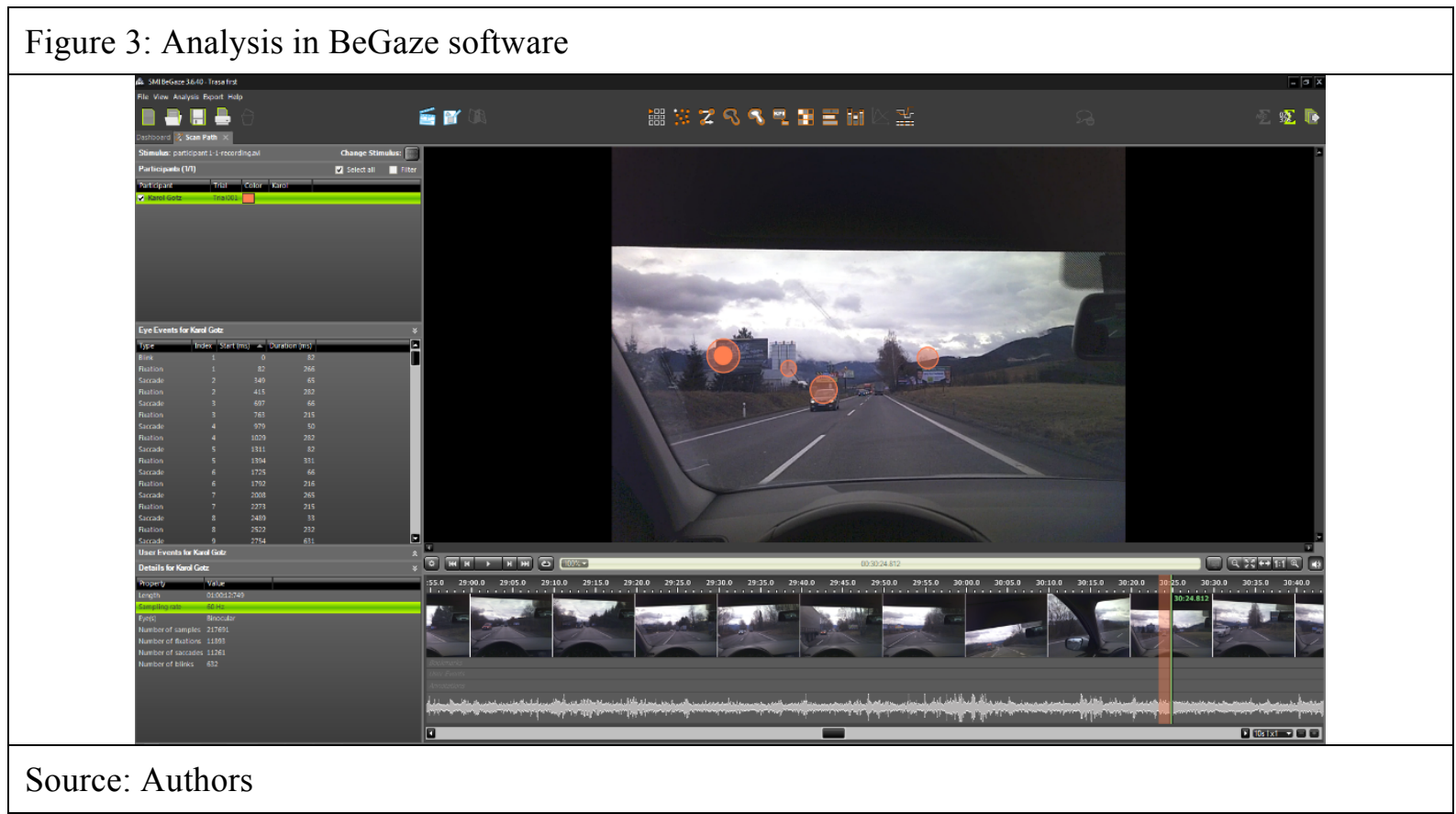

The results of the analysis using BeGaze revealed that, during the trip, the driver looked at 52 of the 130 vertical traffic signs. Thus, the driver missed 78 traffic signs $(60 \%)$. In addition, the average dwelling time on one traffic sign by the driver was 0.233 seconds. Of all traffic signs, the driver missed 28 traffic information signs, 23 traffic warning signs, and 12 traffic prohibition signs, and such misses could lead to traffic accidents in certain circumstances.

In comparison, the driver looked at 165 of the 348 billboards during the trip. That is, the driver looked at more than a third of billboards on average. The average dwelling time on one billboard was 0.543 seconds. The roadside advertisements are placed on either side of roadways, that is, left or right of the 
driver's vision. Previous research described a case where the number of times a driver gazed at the roadside billboards on their left was 40 compared to that of 135 on their right. These findings indicate a potential dangerous situation with the attention of the driver focused away from the main roadway.

A more detailed comparison between the driver's eye movement at the traffic sign and that at the billboard is given in Table 2 .

Table 2: The comparison between the driver's eye movement at the traffic sign and billboard

\begin{tabular}{|l|r|r|}
\hline & Vertical traffic signs & Advertisements \\
\hline The total observing time (sec) & 12.14 & 90.7 \\
\hline The average dwell time (sec) & 0.233 & 0.543 \\
\hline The longest fixation at one object (sec) & 0.8 & 2.0 \\
\hline The highest number of glances at one object & 2 & 5 \\
\hline Source: Authors & & \\
\hline
\end{tabular}

To summarize, roadside billboards seem to affect driver behavior as drivers may be attracted to glance more often and longer at the billboards than at regular traffic signs. Possibly, the main reason for this difference is that when drivers look at the billboard they become interested in the billboard message. Different colors and graphic shapes displayed on the billboard could also influence the dwelling time of a driver's gaze.

\section{Conclusion}

To ensure external validity, data were collected in a real-time study of driving behavior. The statistics for traffic accidents from the Traffic Inspectorate showed that the most common cause of traffic accident was incorrect driving of the driver (in 19 of 21 traffic accidents). Drivers' inattention could lead to incorrect driving that could cause traffic accidents. Regarding traffic signs, changing vertical traffic signs to depict greater motion (e.g., a pedestrian running, instead of walking) may be a simple way to help prevent potentially dangerous accidents.

Most likely, reducing the number of roadside advertisements to half of those existing would reduce the frequency of a driver's eye movement away from the road. The outcome would be decreased travel time spent looking at advertisements, and thus safer roads and decrease in the number and associated costs of traffic accidents. The risk that the driver does not notice the traffic sign would be reduced in this case.

\section{Acknowledgement}

This contribution was undertaken as part of the research project: 1/0721/15 VEGA Research, on the impact of postal services and telecommunication convergence on regulatory approaches in the postal sector.

\section{References}

Beijer, D., Smiley, A. \& Eizenman, M. (2004). Observed Driver Glance Behavior at Roadside Advertising Signs. Transp Res Rec.

Chattington, M., Reed, N., Basacik, D., Flint, A. \& Parkes, A. (2009). Investigating driver distraction: The effects of video and static advertising (No. CPR208). Crowthorne, UK: Transport Research Laboratory.

Edquist, J., Horberry, T., Hosking, S., \& Johnston, I. (2011). Effects of advertising billboards on simulated driving. Appl Ergon.

Johansson, G. \& Rumar, K. (1966). Drivers and road signs: A preliminary investigation of the capacity of car drivers to get information from road signs. Ergon.

Kalasova, A., Faith, P. \& Mikulski, J. (2015) Telematics Applications, an Important Basis for Improving the Road Safety. In: Telematics - support of transport: 15th international conference on Transport systems telematics, Berlin, Springer-Verlag, ISBN 978-3-319-24577-5, p. 414-423

Kubikova, S., Kalasova, A. \& Cernicky, L. (2014). Microscopic simulation of optimal use of communication network. In: Telematics - support of transport: 14th international conference on Transport systems telematics, Berlin, Springer-Verlag, ISBN 978-3-662-45316-2, p. 414-423

Madlenak, R., Madlenakova, L. (2014). Digital advertising system in urban transport system of Žilina town In: Transport and Telecommunication, Vol. 15, Issue 3, P. 215-226 